\title{
P Wave Peak Time for Predicting an Increased Left Atrial Volume Index in Hemodialysis Patients
}

\author{
İbrahim Yıldız ${ }^{\mathrm{a}}$ Pinar Özmen Yildiz ${ }^{\mathrm{a}}$ Cengiz Burak ${ }^{\mathrm{c}}$ İbrahim Rencüzoğulları ${ }^{\mathrm{c}}$ \\ Guner Karaveli Gursoy ${ }^{b}$ Bulent Kayad ${ }^{d}$ Yavuz Karabağ ${ }^{c}$ Metin Çağdaş ${ }^{c}$ \\ ${ }^{a}$ Department of Cardiology, Osmaniye State Hospital, Osmaniye, Turkey; ${ }^{b}$ Department of Nephrology, Osmaniye \\ State Hospital, Osmaniye, Turkey; ' ${ }^{C}$ Department of Cardiology, Faculty of Medicine, Kafkas University, Kars, Turkey; \\ ${ }^{\mathrm{d}}$ Department of Nephrology, Faculty of Medicine, Cukurova University, Adana, Turkey
}

\section{Significance of the Study}

- The left atrial volume index is a predictor of increased cardiovascular risk in hemodialysis patients.

- This study demonstrates an association between the P wave peak time and the echocardiographically measured left atrial volume index.

- Measuring the $\mathrm{P}$ wave peak time duration with an electrocardiogram could help identify high-risk hemodialysis patients with increased left atrial volume indexes.

\section{Keywords}

Electrocardiography · Hemodialysis · Left atrial volume index $\cdot \mathrm{P}$ wave peak time

\begin{abstract}
Objective: An increased left atrial volume index (LAVI) is related to increased mortality in hemodialysis patients. In the present study, we evaluated the association between the LAVI and the P wave peak time (PWPT), a newly introduced electrocardiographic parameter, in hemodialysis patients. Methods: The study population was made up of 79 hemodialysis patients with a mean age of $53 \pm 18$ years ( $55.7 \%$ were males). These patients were divided into a normal LAVI $(\leq 28$ $\left.\mathrm{mL} / \mathrm{m}^{2}\right)$ group $(n=45)$ and an increased LAVI $\left(>28 \mathrm{~mL} / \mathrm{m}^{2}\right)$ group $(n=34)$. The demographic, clinical, laboratory, echocardiographic, and electrocardiographic variables of the
\end{abstract}

groups were compared. Results: The $\mathrm{P}$ wave terminal force from lead V1, P wave dispersion and PWPTs obtained from leads V1 and D2 (PWPT ${ }_{\mathrm{D} 2}$ ) were significantly higher in the patients with increased LAVIs. In multivariable analysis, only the $\mathrm{PWPT}_{\mathrm{D} 2}$ was an independent predictor of an increased LAVI (odds ratio $=1.117,95 \% \mathrm{Cl}=1.052-1.185, p<0.001$ ) The receiver-operating characteristic curve analysis showed that the best PWPT $_{\mathrm{D} 2}$ cutoff value for predicting an increased LAVI was $60 \mathrm{~ms}$, with a sensitivity of $76.5 \%$ and a specificity of $66.7 \%$ (area under the curve $=0.736,95 \% \mathrm{Cl}=0.625-$ $0.829, p<0.001)$. Conclusion: This study showed that a prolonged $\mathrm{PWPT}_{\mathrm{D} 2}$ was independently associated with an increased LAVI in hemodialysis patients. Therefore, measuring the $\mathrm{PWPT}_{\mathrm{D} 2}$ duration on an electrocardiogram may help define high-risk hemodialysis patients with increased LAVIs.

(c) 2019 The Author(s)

Published by S. Karger AG, Basel

\begin{tabular}{ll}
\hline KARGER & $\begin{array}{l}\text { () } 2019 \text { The Author(s) } \\
\text { Published by S. Karger AG, Basel }\end{array}$ Oparger \\
karger@karger.com & This is an Open Access article licensed under the Creative Commons \\
www.karger.com/mpp & $\begin{array}{l}\text { Attribution-NonCommercial-4.0 International License (CC BY-NC) } \\
\text { (http://www.karger.com/Services/OpenAccessLicense), applicable to } \\
\text { the online version of the article only. Usage and distribution for com- } \\
\text { mercial purposes requires written permission. }\end{array}$
\end{tabular}

Ibrahim Yildiz

Department of Cardiology, Osmaniye State Hospital

D.400 Highway, Akyar

TR-80000 Osmaniye (Turkey)

E-Mail ibrahimyildiz79@yahoo.com 


\section{Introduction}

Left atrial volume (LAV) is closely related to left ventricular (LV) diastolic dysfunction and is affected by the factors associated with LV diastolic filling pressure. LAV is considered to be a biomarker of both the severity and the duration of LV diastolic filling pressure [1]. Enlargement of the left atrium (LA) is associated with poor end points and may be useful for estimating cardiovascular events and death $[2,3]$. An increased LAV index (LAVI) has been identified as an important biomarker for chronically increased LV diastolic pressure in hemodialysis patients. Studies have suggested that it could be a predictor of increased cardiovascular risk and mortality in patients with end-stage renal disease (ESRD) [4-6].

Although an echocardiographic assessment of LA enlargement and LV function is standard, it is not always available in clinical practice. However, a 12-lead electrocardiogram (ECG) is a simple, easily accessible and inexpensive tool that can be used to predict the heart cavity volumes and ventricular mass. To date, several of the $P$ wave parameters derived from an ECG, including the $\mathrm{P}$ wave terminal force from lead V1 (PTFV1), P wave dispersion $\left(\mathrm{PW}_{\mathrm{DIS}}\right)$, and the maximum $\mathrm{P}$ wave duration $\left(\mathrm{PWD}_{\mathrm{MAX}}\right)$, have been evaluated for the assessment of LA enlargement and LV diastolic dysfunction in several populations other than ESRD patients [7-11]. Moreover, the $\mathrm{P}$ wave peak time (PWPT) has recently been introduced as an electrocardiographic parameter. A prolonged PWPT has been found to be related to the increased LV diastolic filling pressure and increased LA pressure because of the imperfect reperfusion in patients with anterior S-T segment elevation myocardial infarction [12].

ESRD is strongly associated with impaired LV diastolic function [13]. However, an echocardiographic assessment is not customary, nor is it easily accessible, for hemodialysis patients. The use of easily accessible diagnostic tools such as an ECG for screening for left atrial enlargement, one of the most important findings of diastolic dysfunction, may facilitate early diagnosis and treatment. Therefore, this study aimed at investigating the relationship between the LAVI and the PWPT in hemodialysis patients.

\section{Subjects and Methods}

\section{Study Patients}

This study was conducted on patients with ECG-detected sinus rhythms. They were undergoing standard hemodialysis 3 times per week for at least 6 months. Patients with an inadequate echocar- diographic image quality, ejection fraction of $<50 \%$, significant valvular heart disease, previous history of coronary artery disease and congestive heart failure were excluded. A total of 102 patients who underwent hemodialysis between June 2018 and December 2018 were screened. Nine patients with a history of coronary artery disease, 3 with atrial fibrillation, 5 with inadequate echocardiographic image quality, 4 with significant valvular disease, and 2 with low left ventricular ejection fraction were excluded. The remaining 79 hemodialysis patients constituted the study population.

On the basis of their LAVIs, the patients were classified into a normal LAVI $\left(\leq 28 \mathrm{~mL} / \mathrm{m}^{2}\right)$ group or an increased LAVI $(>28 \mathrm{~mL} /$ $\mathrm{m}^{2}$ ) group, and the two groups were compared [2]. On the same day of blood sample collection, echocardiographic examination was performed immediately after ECG recording. All the enrolled patients provided written informed consent, and the study protocol was approved by the institutional review board. The guidelines for Strengthening the Reporting of Observational Studies in Epidemiology (STROBE) were followed [14].

\section{Collection of Demographic, Clinical, and Laboratory Data}

Demographic and clinical characteristics were obtained from patient interviews and medical records. Each patient's height and weight were measured. In addition, routine laboratory tests were conducted by using fasting blood samples taken on the morning of the interdialytic day before the patient underwent the echocardiographic procedure.

\section{Assessment of ECG}

Each of the patients underwent a standard 12-lead surface ECG, which was recorded at a speed of $25 \mathrm{~mm} / \mathrm{s}$ and a voltage of $10 \mathrm{~mm} / \mathrm{mV}$. All the ECG printouts were assessed qualitatively for the morphology and quantitatively for the intervals with the ImageJ Java image processing program (imagej.nih.gov/ij/). The ECG assessments were performed by two independent cardiologists blinded to the echocardiographic findings of the patients. In case of disagreement, a final decision was reached by consulting a third cardiologist. The $\mathrm{P}$ wave duration measured from the D2 lead $\left(\mathrm{PWD}_{\mathrm{D} 2}\right)$ was defined as the time from the earliest onset of $\mathrm{P}$ wave activity in the D2 lead to the last $\mathrm{P}$ wave activity in this lead [15]. The $\mathrm{PW}_{\text {DIS }}$ was calculated by subtracting the minimum $\mathrm{P}$ wave duration $\left(\mathrm{PWD}_{\mathrm{MIN}}\right)$ from the $\mathrm{PWD}_{\mathrm{MAX}}[16]$. The depth of the terminal negative portion of the $\mathrm{P}$ wave from lead V1 was multiplied by its duration in order to define the PTFV1 [17]. The duration (ms) from the beginning to the peak of the P wave was measured from lead D2 to define the PWPT from the D2 lead (PWPT $\left.\mathrm{P}_{\mathrm{D}}\right)$. The PWPT from the V1 lead ( $\left.\mathrm{PWPT}_{\mathrm{V} 1}\right)$ was measured as the interval between the beginning of the $\mathrm{P}$ wave to the nadir of the negative deflection in patients with biphasic or pure negative $\mathrm{P}$ wave morphology (Fig. 1) [12].

\section{Echocardiographic Assessment}

A transthoracic echocardiographic examination of each patient was performed by an experienced cardiologist using an EPIQ 7 ultrasound system for cardiology (Philips Medical Systems, Bothell, WA, USA) on the interdialytic day [18]. Standard echocardiographic imaging was performed, and the measurements were taken in accordance with the American Society of Echocardiography guidelines. Two-dimensional, Doppler, and tissue Doppler echocardiography were used $[19,20]$. The LV ejection fraction was cal- 
Fig. 1. Measurement of $P$ wave peak time obtained from D2 and V1 leads.

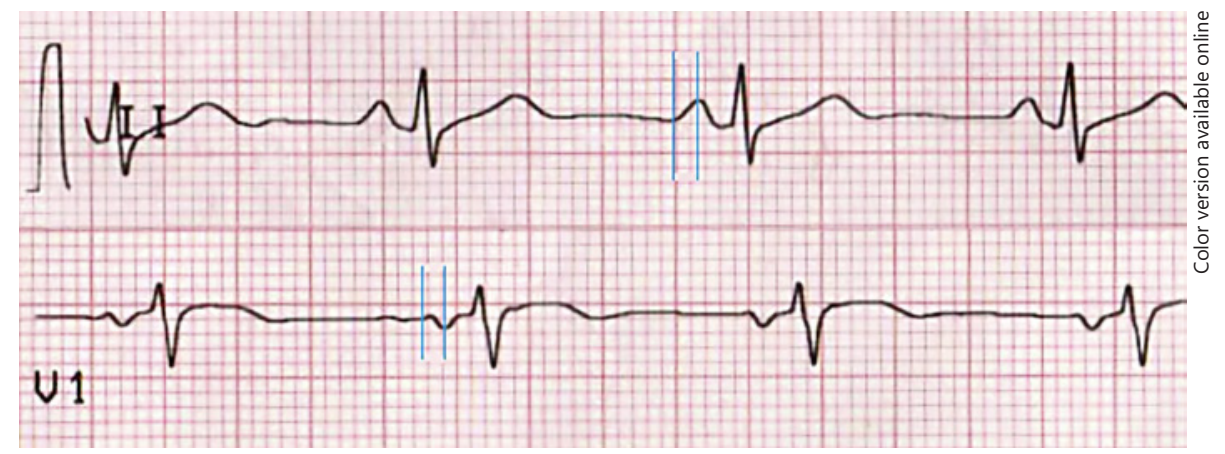

culated with the biplane method (modified Simpson's rule). LAV measurements were done at the end of systole through the use of the biplane disk summation method, and the LV mass measured with the truncated ellipsoid technique at the end of diastole. The LAV and LV mass were indexed by the body surface area to calculate the LAVI $\left(\mathrm{mL} / \mathrm{m}^{2}\right)$ and the LV mass index (LVMI; $\left.\mathrm{g} / \mathrm{m}^{2}\right)$, respectively. The pulsed Doppler sample volume was placed at the tips of the mitral valve leaflets to facilitate the measurement of the peak velocity of the early diastolic transmitral flow $(\mathrm{E}, \mathrm{cm} / \mathrm{s})$, its deceleration time, and the peak velocity of the late diastolic transmitral flow $(\mathrm{A}, \mathrm{cm} / \mathrm{s})$. The tissue Doppler sample volume was placed at the lateral corner of the mitral annulus to enable the measurement of the peak mitral annulus velocity $\left(\mathrm{E}^{\prime}, \mathrm{cm} / \mathrm{s}\right)$ by using the apical 4-chamber view. The E/A and $\mathrm{E} / \mathrm{E}^{\prime}$ ratios were calculated, and echocardiographic measurements were averaged over 3 consecutive heartbeats.

\section{Statistical Analysis}

Statistical analyses were performed with SPSS Statistics for Windows, version 17.0 (SPSS Inc., Chicago, IL, USA), and a $p$ value $<0.05$ was considered to be a statistically significant difference. The demographic, clinical, laboratory, electrocardiographic, and echocardiographic data for the normal LAVI and increased LAVI groups were compared, and the KolmogorovSmirnov test was used to analyze the normality of the data distribution. The continuous variables with normal distributions were presented as means and standard deviations, and those without normal distributions were presented as medians (interquartile ranges). The normal LAVI and increased LAVI group comparison was performed with the Student's $t$ test or the MannWhitney U test, as appropriate. The categorical variables were presented as numbers and percentages, and the normal LAVI and increased LAVI group comparison was performed with the $\chi^{2}$ or Fisher's exact test, as appropriate. The correlation analysis of two continuous variables was performed with Pearson's correlation or Spearman's rank correlation coefficient for the variables with or without normal distributions, respectively. Two multivariable logistic regression models were developed to determine whether the PWPT parameters were independent predictors of an increased LAVI.

In the first model, multivariable logistic regression analyses were performed with the electrocardiographic variables that showed significant differences in the univariate analysis. In the second model, the PWPT parameters and clinical parameters were found to be associated with the increased LAVI observed in previ- ous studies (age, hypertension, and body mass index [BMI]) [21]. A receiver-operating characteristic (ROC) curve analysis was then performed to determine the best $\mathrm{PWPT}_{\mathrm{D} 2}$ cutoff value for predicting an increased LAVI. For ease of use in clinical practice, the sensitivity and specificity of the cutoff value of $60 \mathrm{~ms}$ (1.5 small squares) were also calculated. The reproducibility of the $\mathrm{PWPT}_{\mathrm{D} 2}$ and $\mathrm{PWPT}_{\mathrm{V} 1}$ measurements was tested with the concordance correlation coefficient.

\section{Results}

The study population comprised 79 hemodialysis patients with a mean age of $53 \pm 18$ years ( $55.7 \%$ male). They were assigned to one of two groups on the basis of their echocardiographic LAVI measurements. The patients with LAVIs of $\leq 28 \mathrm{~mL} / \mathrm{m}^{2}$ were placed in the normal LAVI group $(n=45)$, and those with LAVIs of $>28 \mathrm{~mL} /$ $\mathrm{m}^{2}$ were placed in the increased LAVI group $(n=34)$. Table 1 lists the demographic, clinical, and laboratory characteristics of the patients in each group. There was no statistically significant difference between the groups in terms of age, sex, or BMI. The incidences of hypertension, smoking, diabetes mellitus, and hyperlipidemia were similar for the two groups. In addition, the laboratory measurements, including levels of glucose, blood urea nitrogen, creatinine, sodium, potassium, calcium, phosphorus, hemoglobin, and ferritin, were similar.

Table 1 lists the electrocardiographic and echocardiographic characteristics of the patients. The LV ejection fraction, $\mathrm{E}, \mathrm{A}, \mathrm{E} / \mathrm{A}$ ratio, deceleration time, $\mathrm{E}^{\prime}, \mathrm{E} / \mathrm{E}^{\prime}$ ratio, heart rate, QRS duration, bundle branch block frequency, QRS fragmentation frequency, V1 P wave morphology, $\mathrm{PWD}_{\mathrm{D} 2}, \mathrm{PWD}_{\mathrm{MIN}}$, and $\mathrm{PWD}_{\mathrm{MAX}}$ were similar for the groups. However, the LAVI, LVMI, PTFV1, PW $\mathrm{PWPT}_{\mathrm{V} 1}$, and $\mathrm{PWPT}_{\mathrm{D} 2}(56 \pm 14$ vs. $71 \pm 20, p<0.001)$ were significantly higher in the patients with increased LAVIs than in those with normal LAVIs. 
Table 1. Demographic, clinical, laboratory, electrocardiographic, and echocardiographic characteristics of all patients, patients with normal left atrial volume index (LAVI) and increased LAVI with $p$ value

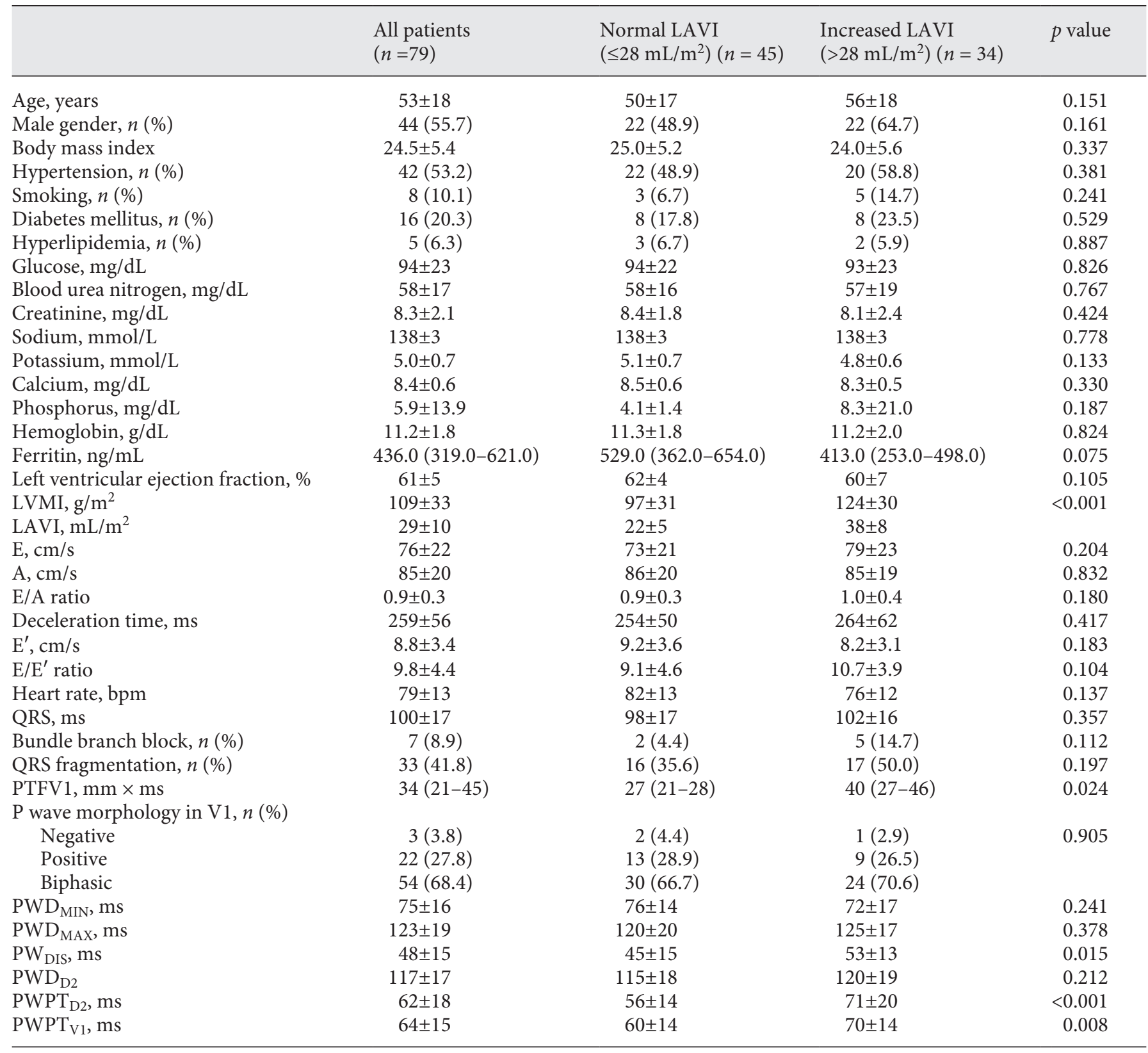

LVMI, left ventricular mass index; PTFV1, P wave terminal force from lead V1; $\mathrm{PWD}_{\mathrm{D} 2}$, P wave duration measured from D2 lead; $\mathrm{PWD}_{\mathrm{DIS}}, \mathrm{P}$ wave dispersion; $\mathrm{PWD}_{\mathrm{MAX}}$, maximum $\mathrm{P}$ wave duration; $\mathrm{PWD}_{\mathrm{MIN}}$, minimum $\mathrm{P}$ wave duration; $\mathrm{PWPT}_{\mathrm{D} 2}, \mathrm{P}_{\text {wave }}$ peak time obtained from D2 lead; $\mathrm{PWPT}_{\mathrm{V} 1}$, P wave peak time obtained from V1 lead.

The results of the correlation analysis of the $\mathrm{P}$ wave parameters, including the PTFV1, $\mathrm{PW}_{\mathrm{DIS}}, \mathrm{PWPT}_{\mathrm{V} 1}$, and $\mathrm{PWPT}_{\mathrm{D} 2}$, with the echocardiographic parameters, including the LAVI, LVMI, E/A ratio and $\mathrm{E} / \mathrm{E}^{\prime}$ ratio are presented in Table 2. The $\mathrm{PWPT}_{\mathrm{V} 1}$ and $\mathrm{PWPT}_{\mathrm{D} 2}$ exhib- ited significantly moderate positive correlations with the LAVI. However, the PTFV1 and PW $\mathrm{PIS}_{\text {IS }}$ exhibited significantly weak positive correlations with the LAVI. The $\mathrm{PW}_{\mathrm{DIS}}, \mathrm{PWPT}_{\mathrm{V} 1}$, and $\mathrm{PWPT}_{\mathrm{D} 2}$ exhibited significantly weak positive correlations with the LVMI. However, the 


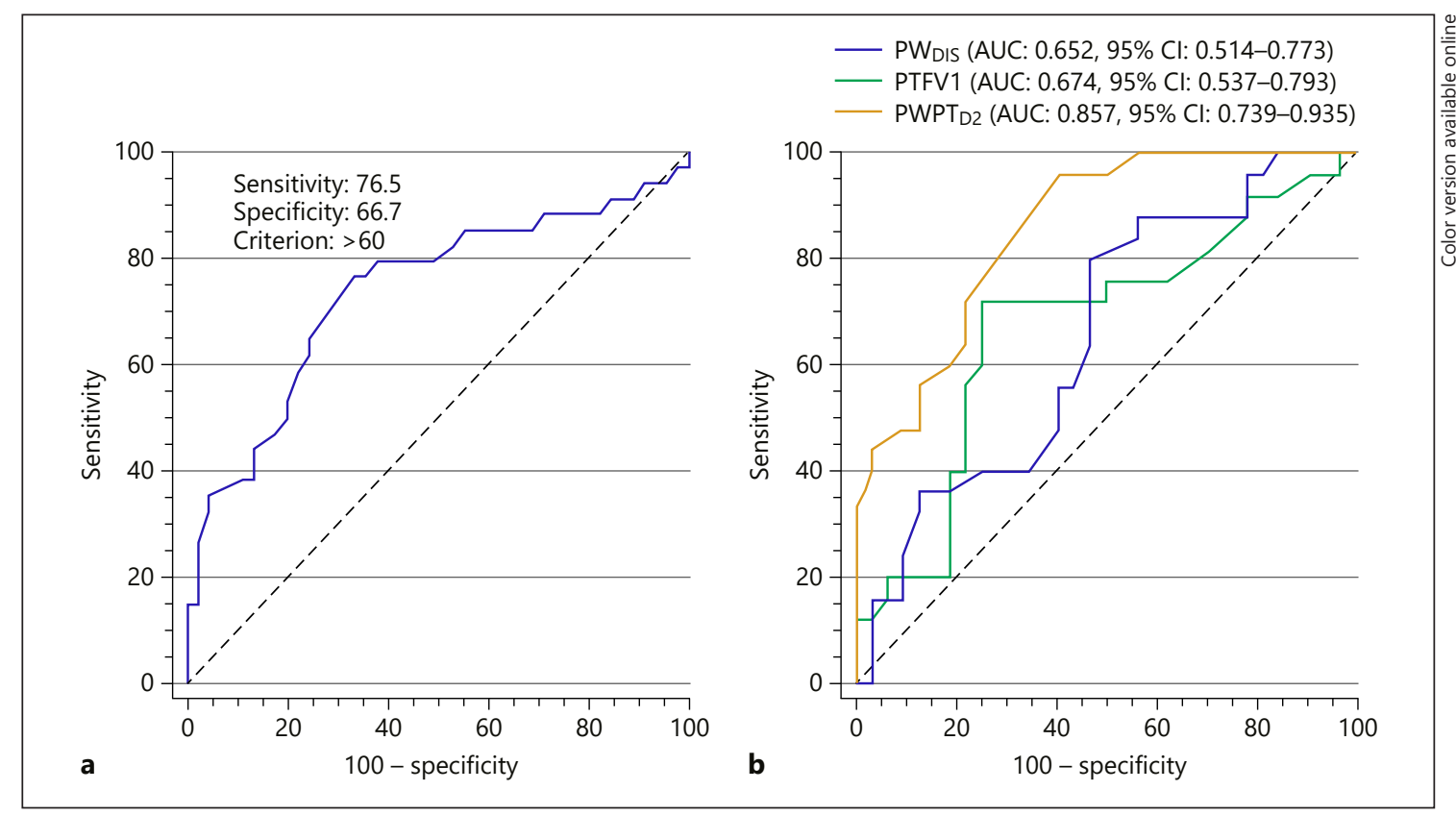

Fig. 2. a Receiver-operating characteristic graphic to detect the best cutoff value of $P W P T_{D 2}$ for increased LAVI $\left(>28 \mathrm{~mL} / \mathrm{m}^{2}\right)$ prediction (area under the curve $=0.736,95 \%$ confidence interval $=0.625-0.829, p<0.001$ ). b Comparison of receiver-operating characteristic curves of $\mathrm{P}$ wave parameters.

Table 2. Correlation analysis of $P$ wave parameters with echocardiographic parameters including LAVI, LVMI, E/A and E/E' ratios

\begin{tabular}{|c|c|c|c|c|}
\hline & $\begin{array}{l}\text { LAVI, } \\
\mathrm{mL} / \mathrm{m}^{2}\end{array}$ & $\begin{array}{l}\text { LVMI, } \\
\mathrm{g} / \mathrm{m}^{2}\end{array}$ & $\begin{array}{l}\mathrm{E} / \mathrm{A} \\
\text { ratio }\end{array}$ & $\begin{array}{l}\mathrm{E} / \mathrm{E}^{\prime} \\
\text { ratio }\end{array}$ \\
\hline \multicolumn{5}{|l|}{$\mathrm{PW}_{\text {DIS }}, \mathrm{ms}$} \\
\hline$r$ value & 0.338 & 0.344 & 0.139 & 0.242 \\
\hline$p$ value & 0.002 & 0.002 & 0.222 & 0.031 \\
\hline$N$ & 79 & 79 & 79 & 79 \\
\hline \multicolumn{5}{|c|}{ PTFV1, $\mathrm{mm} \times \mathrm{ms}$} \\
\hline$r$ value & $0.316^{\mathrm{a}}$ & $0.231^{\mathrm{a}}$ & $-0.150^{\mathrm{a}}$ & $0.090^{\mathrm{a}}$ \\
\hline$p$ value & 0.017 & 0.084 & 0.267 & 0.504 \\
\hline$N$ & 57 & 57 & 57 & 57 \\
\hline \multicolumn{5}{|c|}{$\mathrm{PWPT}_{\mathrm{D} 2}, \mathrm{~ms}$} \\
\hline$r$ value & 0.586 & 0.307 & -0.019 & 0.120 \\
\hline$p$ value & $<0.001$ & 0.006 & 0.871 & 0.294 \\
\hline$N$ & 79 & 79 & 79 & 79 \\
\hline \multicolumn{5}{|c|}{$\mathrm{PWPT}_{\mathrm{V} 1}, \mathrm{~ms}$} \\
\hline$r$ value & 0.580 & 0.266 & 0.053 & 0.075 \\
\hline$p$ value & $<0.001$ & 0.046 & 0.695 & 0.580 \\
\hline$N$ & 57 & 57 & 57 & 57 \\
\hline
\end{tabular}

LAVI, left atrial volume index; LVMI, left ventricular mass index; PTFV1, P wave terminal force from lead V1; $\mathrm{PW}_{\text {DIS }}$ P wave dispersion; $\mathrm{PWPT}_{\mathrm{D} 2}, \mathrm{P}$ wave peak time obtained from $\mathrm{D} 2$ lead; $\mathrm{PWPT}_{\mathrm{V} 1}, \mathrm{P}$ wave peak time obtained from V1 lead. ' Spearman's correlation analysis was used. Pearson analysis was used for the remaining results.
E/A ratio was not correlated with any of the $\mathrm{P}$ wave parameters. The $\mathrm{E} / \mathrm{E}^{\prime}$ ratio exhibited a significantly weak positive correlation with the $\mathrm{PW}_{\text {DIS }}$ only.

The independent predictors of an increased LAVI were identified by multivariable logistic regression analyses through the use of the electrocardiographic variables, including the PTFV1, $\mathrm{PW}_{\mathrm{DIS}}, \mathrm{PWPT}_{\mathrm{V} 1}$ and $\mathrm{PWPT}_{\mathrm{D} 2}$ that showed significant differences in the univariate analysis. The results showed that only the $\mathrm{PWPT}_{\mathrm{D} 2}$ was an independent predictor of an increased LAVI (odds ratio per $1 \mathrm{~ms}$ increase $=1.117,95 \%$ confidence interval $[\mathrm{CI}]=$ $1.052-1.185, p<0.001$; Table 3). In addition, the $\mathrm{PWPT}_{\mathrm{D} 2}$ was found to be an independent predictor of an increased LAVI (odds ratio per $1 \mathrm{~ms}$ increase $=1.054,95 \% \mathrm{CI}=$ $1.021-1.088, p=0.001$ ) in the multivariable logistic regression analyses performed with the clinical variables (age, hypertension, and BMI) that were previously shown to be associated with an increased LAVI.

The ROC curve analysis showed that the best $\mathrm{PWPT}_{\mathrm{D} 2}$ cutoff value for the prediction of an increased LAVI was 60 ms (1.5 small square on ECG), with a sensitivity of $76.5 \%$ and a specificity of $66.7 \%$ (area under the curve [AUC] $=$ $0.736,95 \% \mathrm{CI}=0.625-0.829, p<0.001$; Fig. $2 \mathrm{a})$. The cutoff value of $40 \mathrm{~ms}$ ( 1 small square on the ECG) had a sensitivity and specificity of 91.2 and $11.1 \%$, respectively. 
Table 3. Univariate and multivariable logistic regression analysis of $\mathrm{P}$ wave parameters for increased LAVI $\left(>28 \mathrm{~mL} / \mathrm{m}^{2}\right) \mathrm{prediction}$

\begin{tabular}{|c|c|c|c|c|c|c|}
\hline & \multicolumn{3}{|c|}{ Univariate analysis } & \multicolumn{3}{|c|}{ Multivariable analysis } \\
\hline & odds ratio & $95 \% \mathrm{CI}$ & $p$ value & odds ratio & $95 \% \mathrm{CI}$ & $p$ value \\
\hline $\mathrm{PW}_{\text {DIS }}, \mathrm{ms}$ & 1.042 & $1.006-1.080$ & 0.02 & - & - & - \\
\hline PTFV $1, \mathrm{~mm} \times \mathrm{ms}$ & 1.036 & $1.002-1.070$ & 0.036 & - & - & - \\
\hline $\mathrm{PWPT}_{\mathrm{D} 2}, \mathrm{~ms}$ & 1.054 & $1.021-1.088$ & 0.001 & 1.117 & $1.052-1.185$ & $<0.001$ \\
\hline $\mathrm{PWPT}_{\mathrm{V} 1}, \mathrm{~ms}$ & 1.060 & $1.013-1.109$ & 0.012 & - & - & - \\
\hline
\end{tabular}

CI, confidence interval; LAVI, left atrial volume index; PTFV1, P wave terminal force from lead V1; $\mathrm{PW}_{\mathrm{DIS}}, \mathrm{P}$ wave dispersion; $\mathrm{PWPT}_{\mathrm{D} 2}, \mathrm{P}$ wave peak time obtained from D2 lead; $\mathrm{PWPT}_{\mathrm{V} 1}, \mathrm{P}$ wave peak time obtained from V1 lead.

An ROC curve comparison analysis was performed on 57 patients (i.e., patients for whom the PTFV1 could be calculated) to compare the $\mathrm{P}$ wave parameters. The $\mathrm{PWPT}_{\mathrm{D} 2}$ was a better predictor $(\mathrm{AUC}=0.857,95 \% \mathrm{CI}=$ $0.739-0.935)$ than the PTFV1 $(\mathrm{AUC}=0.674,95 \% \mathrm{CI}=$ $0.537-0.793)$ and the $\mathrm{PW}_{\mathrm{DIS}}(\mathrm{AUC}=0.652,95 \% \mathrm{CI}=$ $0.514-0.773 ; p=0.021$ and $p=0.002$, respectively; Fig. $2 b$ ).

The concordance correlation coefficients of the $\mathrm{PWPT}_{\mathrm{D} 2}$ and $\mathrm{PWPT}_{\mathrm{V} 1}$ measurements, performed by the same observer, were 0.991 (95\% CI $=0.986-0.994)$ and 0.992 (95\% CI $=0.987-0.995)$, respectively. The concordance correlation coefficients of the $\mathrm{PWPT}_{\mathrm{D} 2}$ and PWP$\mathrm{T}_{\mathrm{V} 1}$ measurements, performed by two independent observers, were $0.992(95 \% \mathrm{CI}=0.988-0.995)$ and 0.989 (95\% CI $=0.981-0.993)$, respectively.

\section{Discussion}

This study evaluated the associations between the LAVI and the $\mathrm{P}$ wave parameters in hemodialysis patients. Despite the significant differences between the normal LAVI and increased LAVI groups regarding the PTFV1, PW $\mathrm{PWPT}_{\mathrm{V} 1}$, and $\mathrm{PWPT}_{\mathrm{D} 2}$, only a prolonged $\mathrm{PWPT}_{\mathrm{D} 2}$ was found to be an independent predictor of an increased LAVI. Moreover, the PWPT $\mathrm{D}_{\mathrm{D}}$ was correlated with the LAVI.

Incremental increases in the LAVI are an independent predictor of adverse cardiovascular outcomes in patients on hemodialysis. Treatment strategies, such as maintaining a euvolemic state and avoiding overly rapid fluid removal, are efforts to halt the increase in the LAVI in patients on hemodialysis. Given the known prognostic value of the LAVI in hemodialysis patients, it has been an accepted surrogate end point in several studies as treatment target $[22,23]$. Therefore, close surveillance of the LAVI of these patients is helpful for monitoring cardiovascular risk and optimizing dialysis therapy.

P Wave Peak Time and Left Atrial Volume Index
Atrial stretching resulting from LA pressure overload and LA enlargement could change the electrophysiological properties of the LA myocardium. This can be interpreted on a surface ECG $[12,24,25]$. The $P$ wave parameters derived from an ECG have been shown to be associated and correlated with the LAVI in patient populations other than hemodialysis patients $[8,9]$. However, the subanalysis of one study showed that there was no association between the $\mathrm{PW}_{\text {Dis }}$ and the LA diameter in hemodialysis patients [26]. The measurements were not taken simultaneously in that study; the LA diameter, rather than the LAVI, was used. In the present study, the measurements were taken simultaneously. The PTFV1, $\mathrm{PW}_{\mathrm{DIS}}, \mathrm{PWPT}_{\mathrm{V} 1}$, and $\mathrm{PWPT}_{\mathrm{D} 2}$ were all correlated with the LAVI; however, the correlations were weak for the PTFV1 and $\mathrm{PW}_{\mathrm{DIS}}$, and moderate for the $\mathrm{PWPT}_{\mathrm{V} 1}$ and $\mathrm{PWPT}_{\mathrm{D} 2}$. After the multivariable logistic regression analysis had been performed, only a prolonged $\mathrm{PWPT}_{\mathrm{D} 2}$ was found to be an independent predictor of an increased LAVI. Therefore, the $\mathrm{PWPT}_{\mathrm{D} 2}$ might better reflect the electrophysiological changes resulting from the pressure overload and dilatation of the left atrium.

In previous studies, the LAVI was found to be associated with the diastolic dysfunction grade [1, 27]. Although the $\mathrm{E} / \mathrm{E}^{\prime}$ ratio was higher in the increased LAVI group, this difference did not reach statistical significance because of the low number of cases in the present study. Moreover, no statistically significant difference was found between the groups regarding the E/A ratio and deceleration time because the increased LAVI group might have contained patients exhibiting all of the stages of diastolic dysfunction. This would have included impaired relaxation, pseudonormalization, and a restrictive filling pattern. Previous studies have reported a correlation between the degree of LA enlargement and the LV mass [1, 27]. The results of the present study confirm those of previous studies: the increased LAVI group exhibited a significantly higher LVMI than the normal LAVI group. 
This study has several limitations. For example, the sample size was relatively small; therefore, the results need to be validated by larger studies. Because a crosssectional design was employed, data on the patient prognoses and the temporal changes in the electrocardiographic and echocardiographic parameters are not available. Further prospective studies are needed to assess the clinical effects of these results. The LA volume was measured with two-dimensional echocardiography, which is not as specific and sensitive as cardiac computed tomography or magnetic resonance imaging. In addition, the increased risk of electrolyte imbalance and disturbances in cardiac conduction in ESRD patients might have affected the study results. Moreover, the $\mathrm{PWPT}_{\mathrm{D} 2}$ cutoff value used to predict an increased LAVI was derived from hemodialysis patients; thus, it cannot be extended to other patient populations.

\section{Conclusion}

This study demonstrated that a prolonged $\mathrm{PWPT}_{\mathrm{D} 2}$ was independently associated with an increased LAVI in hemodialysis patients. This could be a more useful sur- rogate for an increased LAVI, especially when compared to the effectiveness of the previously identified parameters $\left(\mathrm{PWD}_{\mathrm{MAX}}, \mathrm{PTFV} 1\right.$, and $\left.\mathrm{PW}_{\mathrm{DIS}}\right)$. For a majority of hemodialysis patients, considerations of the increased likelihood of diastolic dysfunction and the difficulty of access to echocardiography can be addressed by the measurement of the $\mathrm{PWPT}_{\mathrm{D} 2}$ with an ECG to facilitate the identification of the patients with increased LAVIs. Thus, the use of easily obtainable diagnostic tools, such as the PWTP, for screening left atrial enlargement, which is one of the most important findings for diastolic dysfunction, could allow for early diagnosis and treatment.

\section{Statement of Ethics}

All the enrolled patients provided written informed consent, and the study protocol was approved by the institutional review board. All study procedures were conducted according to the Declaration of Helsinki.

\section{Disclosure Statement}

The authors declare that there is no conflict of interest.

\section{References}

1 Tsang TS, Barnes ME, Gersh BJ, Bailey KR, Seward JB. Left atrial volume as a morphophysiologic expression of left ventricular diastolic dysfunction and relation to cardiovascular risk burden. Am J Cardiol. 2002 Dec; 90(12):1284-9.

2 Lang RM, Bierig M, Devereux RB, Flachskampf FA, Foster E, Pellikka PA, et al.; Chamber Quantification Writing Group; American Society of Echocardiography's Guidelines and Standards Committee; European Association of Echocardiography. Recommendations for chamber quantification: a report from the American Society of Echocardiography's Guidelines and Standards Committee and the Chamber Quantification Writing Group, developed in conjunction with the European Association of Echocardiography, a branch of the European Society of Cardiology. J Am Soc Echocardiogr. 2005 Dec;18(12):1440-63.

3 Patel DA, Lavie CJ, Milani RV, Ventura HO. Left atrial volume index predictive of mortality independent of left ventricular geometry in a large clinical cohort with preserved ejection fraction. Mayo Clin Proc. 2011 Aug; 86(8):730-7.

4 Barberato SH, Pecoits Filho R. Prognostic value of left atrial volume index in hemodialysis patients. Arq Bras Cardiol. 2007 Jun;88(6): 643-50.
5 Choi MJ, Kim JK, Kim SG, Yoon JW, Koo JR, $\mathrm{Kim} \mathrm{HJ}$, et al. Left atrial volume index is a predictor of silent myocardial ischemia in highrisk patients with end-stage renal disease. Int J Cardiovasc Imaging. 2013 Oct;29(7):14339.

6 Kim SJ, Han SH, Park JT, Kim JK, Oh HJ, Yoo $\mathrm{DE}$, et al. Left atrial volume is an independent predictor of mortality in CAPD patients. Nephrol Dial Transplant. 2011 Nov;26(11): 3732-9.

7 Jin L, Weisse AB, Hernandez F, Jordan T. Significance of electrocardiographic isolated abnormal terminal P-wave force (left atrial abnormality). An echocardiographic and clinical correlation. Arch Intern Med. 1988 Jul; 148(7):1545-9.

8 Birkbeck JP, Wilson DB, Hall MA, Meyers DG. P-wave morphology correlation with left atrial volumes assessed by 2-dimensional echocardiography. J Electrocardiol. 2006 Apr; 39(2):225-9.

9 Kim DH, Kim GC, Kim SH, Yu HK, Choi WG, An IS, et al. The relationship between the left atrial volume and the maximum $\mathrm{P}$-wave and $\mathrm{P}$-wave dispersion in patients with congestive heart failure. Yonsei Med J. 2007 Oct; 48(5):810-7.
10 Gunduz H, Binak E, Arinc H, Akdemir R, Ozhan H, Tamer A, et al. The relationship between $\mathrm{P}$ wave dispersion and diastolic dysfunction. Tex Heart Inst J. 2005;32(2):163-7.

11 Tsai WC, Lee KT, Wu MT, Chu CS, Lin TH, Hsu PC, et al. Significant correlation of Pwave parameters with left atrial volume index and left ventricular diastolic function. Am J Med Sci. 2013 Jul;346(1):45-51.

12 Çağdaş M, Karakoyun S, Rencüzoğulları İ, Karabağ Y, Yesin M, Gürsoy MO, et al. P wave peak time; a novel electrocardiographic parameter in the assessment of coronary no-reflow. J Electrocardiol. 2017 Sep - Oct;50(5):584-90.

13 Pecoits-Filho R, Bucharles S, Barberato SH. Diastolic heart failure in dialysis patients: mechanisms, diagnostic approach, and treatment. Semin Dial. 2012 Jan-Feb;25(1):35-41.

14 Vandenbroucke JP, von Elm E, Altman DG, Gøtzsche PC, Mulrow CD, Pocock SJ, et al.; STROBE Initiative. Strengthening the Reporting of Observational Studies in Epidemiology (STROBE): explanation and elaboration. Int J Surg. 2014 Dec;12(12):1500-24.

15 Stafford PJ, Kolvekar S, Cooper J, Fothergill J, Schlindwein F, deBono DP, et al. Signal averaged $\mathrm{P}$ wave compared with standard electrocardiography or echocardiography for prediction of atrial fibrillation after coronary bypass grafting. Heart. 1997 May;77(5):417-22. 
16 Dilaveris PE, Gialafos EJ, Sideris SK, Theopistou AM, Andrikopoulos GK, Kyriakidis M, et al. Simple electrocardiographic markers for the prediction of paroxysmal idiopathic atrial fibrillation. Am Heart J. 1998 May;135(5 Pt 1):733-8.

17 Morris JJ Jr, Estes EH Jr, Whalen RE, Thompson HK Jr, McIntosh HD. P-Wave Analysis in Valvular Heart Disease. Circulation. 1964 Feb;29(2):242-52.

18 Barberato SH, Pecoits-Filho R. [Echocardiographic alterations in patients with chronic kidney failure undergoing hemodialysis]. Arq Bras Cardiol. 2010 Jan;94(1):140-6. Portuguese.

19 Gottdiener JS, Bednarz J, Devereux R, Gardin J, Klein A, Manning WJ, et al.; American Society of Echocardiography. American Society of Echocardiography recommendations for use of echocardiography in clinical trials. J Am Soc Echocardiogr. 2004 Oct;17(10): 1086-119.
20 Lang RM, Badano LP, Mor-Avi V, Afilalo J, Armstrong A, Ernande L, et al. Recommendations for cardiac chamber quantification by echocardiography in adults: an update from the American Society of Echocardiography and the European Association of Cardiovascular Imaging. J Am Soc Echocardiogr. 2015; 28(1):1-39. e14.

21 Secundo Junior JA, Santos MA, Faro GB, Soares CB, Silva AM, Secundo PF, et al. Left atrial volume index and prediction of events in acute coronary syndrome: solar Registry. Arq Bras Cardiol. 2014 Oct;103(4):282-91.

22 Law TK, Wald R, Goldstein M, Karur GR, Ng MY, Wang AY, et al. Left atrial remodeling assessed by cardiac MRI after conversion from conventional hemodialysis to in-centre nocturnal hemodialysis. J Nephrol. 2019 Apr; 32(2):273-81.

23 Kim JK, Song YR, Park G, Kim HJ, Kim SG. Impact of rapid ultrafiltration rate on changes in the echocardiographic left atrial volume index in patients undergoing haemodialysis: a longitudinal observational study. BMJ Open. 2017 Feb;7(2):e013990.
24 Ravelli F, Masè M, del Greco M, Marini M, Disertori M. Acute atrial dilatation slows conduction and increases AF vulnerability in the human atrium. J Cardiovasc Electrophysiol. 2011 Apr;22(4):394-401.

25 Li Q, Gu LD, Zhang C, Liu W, Peng Y, Chai $\mathrm{H}$, et al. A Predictive Study of the Dynamic Development of the P-Wave Terminal Force in Lead V1 in the Electrocardiogram in Relation to Long-Term Prognosis in Non-ST-Segment Elevation Acute Coronary Syndrome Patients during Hospitalization. Ann Noninvasive Electrocardiol. 2015 Nov;20(6):54253.

26 Chen SC, Su HM, Huang JC, Chang K, Tsai YC, Chen LI, et al. Association of P-Wave Dispersion with Overall and Cardiovascular Mortality in Hemodialysis Patients. Am J Nephrol. 2015;42(3):198-205.

27 Pritchett AM, Mahoney DW, Jacobsen SJ, Rodeheffer RJ, Karon BL, Redfield MM. Diastolic dysfunction and left atrial volume: a population-based study. J Am Coll Cardiol. 2005 Jan;45(1):87-92. 